\title{
Disappearance of helicobacter without antibiotics in 12 patients with gastritis
}

\author{
HUGH JAMES FREEMAN MD
}

\begin{abstract}
HJ FREEMAN. Disappearance of helicobacter without antibiotics in 12 patients with gastritis. Can J Gastroenterol 1997;11(2): 167-172. Detection of Helicobacter pylori in endoscopic gastric biopsies has been associated with a variety of diseases, including ulcers and gastritis. Although the natural history of $H$ pylori in the gastric mucosa is unknown, antibiotic regimens have been used for eradication. Gastric biopsies from 6050 endoscopic procedures done by a single gastroenterologist from 1981 to 1994 were evaluated. Of these, 2860 from April 1, 1991 to September 30, 1994 had silver-stained biopsies to facilitate $\mathrm{H}$ pylori detection, and at least two upper endoscopic procedures were done with gastric biopsies in 188 patients. Twelve of the 188 patients with an initially positive $H$ pylori gastric biopsy became $H$ pylori-negative without antibiotic treatment for $\mathrm{H}$ pylori or other infection; 10 received omeprazole and two received no drug treatment. In two of the 12 patients recurrent $H$ pylori in the gastric mucosa was also documented. These findings indicate that $\mathrm{H}$ pylori may disappear and reappear in the gastric mucosa with no specific antibiotic eradication regimen, although omeprazole may eradicate $\mathrm{H}$ pylori in vivo in some patients. The natural history of $\mathrm{H}$ pylori in gastric biopsies is poorly understood. Improved understanding, especially regarding the pathogenesis of upper gastrointestinal ulcerative and inflammatory disease processes, is essential before recommendations for specific antibiotic eradication regimens can be made.
\end{abstract}

Key Words: Acid inhibition, Antibiotic therapy, Controls, Gastritis, Helicobacter pylori, Placebo, Ulcer disease

\section{Disparition d'Helicobacter sans antibiotiques chez 12 patients atteints de gastrite}

RÉSUMÉ : La présence d'Helicobacter pylori confirmée lors de biopsies gastriques avec endoscopie a été associée à diverses maladies, y compris aux ulcères et à la gastrite. Bien que l'histoire naturelle de $H$. pylori dans la muqueuse gastrique soit inconnue, des schémas d'antibiothérapie ont été utilisés pour son éradication. Les biopsies gastriques provenant de 6050 interventions endoscopiques effectuées par un seul gastro-entérologue entre 1981 et 1994 sont passées en revues. Parmi ces biopsies, 2 860, recueillies entre le $1^{\text {er }}$ avril 1991 et le 30 septembre 1994, étaient à l'argentaffine, pour faciliter le dépistage de H. pylori et au moins deux interventions endoscopiques des voies supérieures ont été effectuées avec biopsie gastrique chez 188 patients. Douze des 188 patients porteurs à l'origine d'une biopsie gastrique positive à l'égard de $H$. pylori sont devenus $H$. pylori-négatifs sans antibiothérapie contre $H$. pylori ou une autre infection. Dix ont reçu de l'oméprazole et deux n'ont reçu aucun traitement médicamenteux. Chez deux patients sur douze, une récurrence de $H$. pylori dans la muqueuse gastrique a également été documentée. Ces observations donnent à penser que $H$. pylori peut disparaître et réapparaître dans la muqueuse gastrique, sans éradication antibiotique spécifique, bien que l'oméprazole puisse éradiquer $H$. pylori in vivo chez certains patients. L'histoire naturelle de $H$. pylori dans les biopsies gastriques est mal comprise. Il est essentiel de mieux comprendre notamment la pathogenèse des processus pathologiques ulcéreux et inflammatoires des voies digestives supérieures avant de formuler des recommandations relativement au schéma d'antibiothérapie d'éradication spécifique.
$\mathrm{C}$ olonization of the gastric mucosa with Helicobacter pylori has been associated with gastritis and ulcer disease. In 1983 Warren (1) and Marshall (2) reported detection of an 'unidentified' curved bacilli, similar to other Campylobacter species, in gastric mucosa. Subsequently Marshall et al (3) reported development of a self-limited gastritis after cimetidine pretreatment and ingestion of a cultured isolate; of note, the bacteria were found in gastric biopsies 10 days later but not 14 days after ingestion. Tinidazole treatment was then administered with concomitant symptom resolution. This 
TABLE 1

Summary of clinical data

\begin{tabular}{|c|c|c|c|c|c|}
\hline Age/sex & Pain & Ulcer* (total n) & NSAIDs & Other $^{\dagger}$ & $\begin{array}{c}\text { Drug } \\
\text { treatment }^{\ddagger}\end{array}$ \\
\hline $78 / \mathrm{F}$ & Yes & GU (3) & No & None & $\mathrm{OMEP}+\mathrm{CIS}$ \\
\hline 68/M & Yes & $\mathrm{E}, \mathrm{GU}(3)^{\S}$ & No & None & OMEP \\
\hline 39/M & Yes & $\mathrm{E}, \mathrm{GU}(2)^{\S}$ & Yes & None & OMEP \\
\hline 57/F & Yes & $\mathrm{E}, \mathrm{GU}, \mathrm{DU}^{\S}$ & No & None & OMEP \\
\hline $61 / F$ & Yes & $\mathrm{GU}(2)^{\S}$ & No & None & OMEP \\
\hline 63/M & Yes & E & No & None & OMEP \\
\hline $57 / M$ & Yes & $D U^{\star *}$ & No & None & OMEP \\
\hline $62 / M$ & Yes & $\mathrm{GU}(3)^{\S}$ & No & None & OMEP \\
\hline $65 / F$ & No & None & No & $C D$ & None \\
\hline $43 / F$ & Yes & None & No & None & None \\
\hline $57 / M$ & Yes & $G U^{\S}$ & Yes & None & OMEP \\
\hline 53/M & Yes & GU,DU $(2)^{\S}$ & Yes & None & OMEP \\
\hline
\end{tabular}

${ }^{*}$ Endoscopic documentation of ulcer disease; ${ }^{\dagger}$ Other gastric or duodenal diseases; ${ }^{\ddagger}$ Drug treatment for gastritis; ${ }^{\S}$ At least one active ulcer with gastritis and positive silver stains for Helicobacter pylori; ${ }^{*}$ Surgical treatment of duodenal erosions and/or ulcer (DU). CD Celiac disease on gluten-free diet; CIS Cisapride; E Erosive esophagitis or esophageal ulcer; F Female; GU Gastric erosions and/or ulcer; M Male; NSAID Nonsteroidal anti-inflammatory drug; OMEP Omeprazole

reported sequence has been widely cited as strong evidence that the bacteria caused the gastritis. Interestingly, these results could not be confirmed in a subsequent volunteer study by different investigators despite use of the same 'Marshall strain' of the bacteria (4).

Detection of $H$ pylori is possible with any one of multiple testing procedures. Recently invasive and noninvasive tests were compared (5). Silver-based staining methods (eg, Warthin-Starry stain) of the gastric antral mucosa were most sensitive (93.1\%) and specific (99.0\%) for detection of H pylori; combined with information from hematoxylin and eosin-stained biopsies, the precision of $H$ pylori diagnosis with gastritis approaches $100 \%$.

Biopsy of gastric mucosa to complement visual observation during upper gastrointestinal endoscopy has become an almost routine clinical practice in many centres. As a result, H pylori detection has become frequent in patients with abdominal pain, dyspepsia or biopsy-defined gastritis. In a personal survey of upper gastrointestinal endoscopy results I noted that, if serial biopsies were done, occasional patients had apparent resolution of $H$ pylori. The present report is based on a formal evaluation of endoscopic biopsy experience over 42 months, from April 1, 1991 to September 30, 1994. Twelve patients were discovered with serial gastric biopsies initially showing $\mathrm{H}$ pylori that disappeared from later biopsies with no antibiotic treatment.

\section{PATIENTS AND METHODS}

The computerized medical records system for the University Hospital (University of British Columbia site), the files for the gastroenterology clinic at the same hospital and the author's office files were explored for all patients who had gastric biopsies during upper gastrointestinal endoscopy from October 1, 1981 to September 30, 1994. A total of 6050 procedures were done. Patients who had upper gastrointesti- nal endoscopy without gastric biopsy, done either for diagnostic or therapeutic purposes, were excluded from this evaluation. A further 3190 patients with upper gastrointestinal endoscopy and gastric biopsies done before April 1, 1991 were excluded because these biopsies had not been routinely stained with silver for $H$ pylori detection (5), leaving 2860 upper gastrointestinal endoscopies with gastric biopsies for review. In this group of 2860, 188 patients had two or more upper gastrointestinal endoscopies with gastric biopsies. Biopsies from at least two sites in the gastric antrum or biopsies from both the gastric antrum and body were done $(6,7)$. Biopsies from the gastric antrum were obtained within 2 to $3 \mathrm{~cm}$ of the pylorus $(6,7)$. Serially sectioned and paraffin-embedded slides from the gastric biopsies had been stained with both hematoxylin and eosin as well as silver (5) to facilitate detection of $\mathrm{H}$ pylori.

Patients were further excluded from the group of 188 if the gastric biopsy from the second upper gastrointestinal endoscopy was positive for $\mathrm{H}$ pylori. Patients were also excluded if antibiotics had been either administered to treat $\mathrm{H}$ pylori directly or received for some other intercurrent infection that may have indirectly treated $\mathrm{H}$ pylori (this was confirmed with the assistance of computerized pharmacy records). Finally, patients were excluded if antibiotics were required for prophylaxis to perform an endoscopic procedure (eg, prosthetic cardiac valve).

A final group of 12 patients resulted for retrospective review. These cases are summarized in Table 1 and details of each case follows.

Case 1: A 78-year-old female was evaluated in January 1993 for epigastric pain and constipation. Prior history included a gastric ulcer, documented with upper gastrointestinal endoscopy, and gallstones. Upper gastrointestinal endoscopy showed a lesser curvature gastric ulcer, and biopsies showed gastritis only with $H$ pylori. Her pain resolved with omeprazole $20 \mathrm{mg} /$ day for 28 days. In March 1993 colonoscopy and biopsies done for constipation revealed melanosis coli. In February 1994 epigastric pain recurred, and omeprazole $20 \mathrm{mg} /$ day for 28 days was started. After treatment upper gastrointestinal endoscopy was normal, but gastric antral biopsies revealed persistent gastritis and $\mathrm{H}$ pylori. Abdominal sonogram showed a gallstone. Another course of omeprazole $20 \mathrm{mg} /$ day for 28 days was prescribed, along with concomitant cisapride $10 \mathrm{mg}$ tid. After one more month, upper gastrointestinal endoscopy and gastric antral and body biopsies were normal with no H pylori. In November 1994 epigastric pain recurred. Trials of ranitidine and famotidine had no symptom-relieving effects. In December 1994 upper gastrointestinal endoscopy showed a gastric ulcer; biopsies showed gastritis only with $H$ pylori. Additional studies to characterize this $H$ pylori strain further were not done. She was treated with omeprazole $20 \mathrm{mg} /$ day for two months. In February 1995 upper gastrointestinal endoscopy confirmed complete ulcer healing. No endoscopic biopsies were repeated.

Case 2: A 68-year-old male developed abdominal pain in December 1992. Barium radiographs showed two gastric ulcers. He was treated with ranitidine and cisapride. Pain 
symptoms recurred. In October 1993 upper gastrointestinal endoscopy showed esophagitis with linear erosions and ulceration, as well as a distal antral gastric ulcer. Biopsies from gastric antral mucosa near the ulcer showed gastritis with H pylori. Pain resolved with omeprazole $40 \mathrm{mg} /$ day for 28 days. In November 1993 upper gastrointestinal endoscopy showed a normal esophagus; the gastric ulcer was healed. Biopsies following drug treatment from the gastric antrum showed persistent gastritis but no $\mathrm{H}$ pylori.

Case 3: A 39-year-old male had abdominal pain, symptoms of gastroesophageal reflux and intermittently had used ibuprofen. He was treated with ranitidine. In April 1992 upper gastrointestinal endoscopy showed gastric antral erosions and a small gastric antral gastric ulcer. Biopsies of the intervening gastric mucosa were normal with no gastritis but $H$ pylori was detected. Ibuprofen was discontinued and a 28-day course of omeprazole $20 \mathrm{mg} /$ day was given. Pain resolved but a second upper gastrointestinal endoscopy after the course of medication showed persistent gastric erosions; biopsies of intervening gastric antral mucosa were normal with no $H$ pylori.

Case 4: A 57-year-old female presented with abdominal pain that was treated with ranitidine. In April 1992 an upper gastrointestinal endoscopy showed linear esophageal erosions, a prepyloric gastric ulcer and duodenal erosions. Biopsies from the ulcer margin showed gastritis with $\mathrm{H}$ pylori. Omeprazole $20 \mathrm{mg} /$ day was given for 28 days. In May 1992 following drug therapy, an upper gastrointestinal endoscopy showed healing of the esophageal, gastric and duodenal mucosa. Gastric antral and body biopsies were normal with no H pylori seen.

Case 5: A 61-year-old female had abdominal pain despite antacids and famotidine. In March 1993 upper gastrointestinal endoscopy showed two gastric ulcers in the distal gastric antrum. Gastric antral biopsies showed inflammatory changes only with $\mathrm{H}$ pylori. Famotidine was continued. In April 1993 upper gastrointestinal endoscopy showed complete healing of the gastric ulcer. No biopsies were done. Pain recurred in April 1994 and omeprazole 20 mg/day was administered. After one month, an upper gastrointestinal endoscopy following drug treatment showed a gastric ulcer. Biopsies of the gastric antrum showed gastritis but no H pylori.

Case 6: A 63-year-old male had heartburn and reflux symptoms previously treated with ranitidine. There was a family history of gastric cancer. In March 1992 upper gastrointestinal endoscopy revealed esophagitis with esophageal ulceration; the gastric mucosa was normal but biopsies from the gastric antrum showed gastritis with $\mathrm{H}$ pylori. Omeprazole $20 \mathrm{mg} /$ day for 28 days was given. In June 1992 reflux symptoms recurred. Upper gastrointestinal endoscopy was normal but biopsies showed gastritis with $H$ pylori. A course of domperidone maleate $10 \mathrm{mg}$ tid was administered, and reflux symptoms resolved. In October 1992 reflux symptoms recurred but upper gastrointestinal endoscopy was normal. Biopsies showed gastritis with H pylori. Omeprazole $20 \mathrm{mg} /$ day was given in March 1993 because epigastric pain with reflux symptoms recurred. An upper gastrointestinal endoscopy was normal, and biopsies of the gastric antrum and body after completion of drug therapy showed gastritis but no H pylori.

Case 7: A 57-year-old male with a duodenal ulcer (diagnosed with upper gastrointestinal endoscopy in July 1987) was treated with vagotomy and pyloroplasty. He had a history of cholecystectomy for gallstones. In October 1988 barium radiographs showed thickened gastric folds, and upper gastrointestinal endoscopy with biopsies indicated gastritis. In September 1992 he was evaluated for abdominal pain. Upper gastrointestinal endoscopy revealed prominent gastric mucosal folds, and biopsies showed gastritis with $H$ pylori, as previously reported elsewhere (8). He was treated with omeprazole $20 \mathrm{mg} /$ day for three months. In July 1993 epigastric pain recurred. Upper gastrointestinal endoscopy and gastric biopsies showed no $\mathrm{H}$ pylori.

Case 8: A 62-year-old male presented with epigastric pain. In February 1985 upper gastrointestinal endoscopy revealed a gastric ulcer and biopsies revealed gastritis. He was treated with cimetidine. In March 1985 upper gastrointestinal endoscopy showed that the gastric ulcer was healed. In February 1986 epigastric pain recurred and upper gastrointestinal endoscopy showed another gastric ulcer; biopsies revealed gastritis. After ranitidine treatment, an upper gastrointestinal endoscopy in March 1986 revealed that his gastric ulcer was healed. In October 1986 epigastric pain recurred. Upper gastrointestinal endoscopy with gastric biopsies showed gastritis, so he was treated with cimetidine. In April 1989 upper gastrointestinal endoscopy was done for epigastric pain; gastric biopsies were normal. In April 1991 epigastric pain recurred with no response to therapeutic trials of cimetidine and ranitidine. Upper gastrointestinal endoscopy and gastric antral biopsies showed gastritis with $H$ pylori. Omeprazole $20 \mathrm{mg} /$ day was given for 28 days, with resolution of epigastric pain. In January 1993 his epigastric pain recurred, and upper gastrointestinal endoscopy showed a gastric ulcer. Biopsies from the gastric antrum and body showed gastritis but no $\mathrm{H}$ pylori. Omeprazole $20 \mathrm{mg} /$ day was given for 28 days and his pain resolved. In February 1993 following drug treatment, upper gastrointestinal endoscopy revealed healing of the gastric ulcer with normal gastric antral and body biopsies and no $H$ pylori.

Case 9: A 65-year-old female was evaluated in February 1993 for diarrhea. Upper gastrointestinal endoscopy and flexible sigmoidoscopy were done with gastric, small bowel and colonic biopsies, which showed gastritis with $H$ pylori, a severe 'flat' mucosal lesion of the small intestine consistent with untreated celiac disease and lymphocytic colitis (9). Although lymphocytic gastritis was previously reported in celiac disease (10) as well as with $H$ pylori (11), biopsies of the gastric mucosa showed a superficial gastritis without excessive epithelial lymphocytosis with $H$ pylori. She was treated with a gluten-free diet. In April 1993 upper gastrointestinal endoscopy with gastric and small intestinal biopsies showed normal gastric antral and body mucosa with no $\mathrm{H}$ pylori and a small intestinal histological response to gluten restriction. 
She remained on a gluten-free diet. In April 1995 upper gastrointestinal endoscopy with gastric and small intestinal biopsies were done; gastric antral and body mucosa were normal with no H pylori. The small intestinal biopsies showed improvement with the gluten-free diet.

Case 10: A 43-year-old female developed abdominal pain and diarrhea alternating with constipation. Upper gastrointestinal endoscopy and gastric biopsies done in January 1989 were normal. In July 1990 a flexible sigmoidoscopy showed diverticulosis. In April 1991 epigastric pain developed. Upper gastrointestinal endoscopy and biopsies showed gastritis with $H$ pylori. An added-fibre diet was suggested. In September 1991 epigastric pain recurred. Upper gastrointestinal endoscopy and gastric antral mucosal biopsies were normal with no $H$ pylori.

Case 11: A 57-year-old male had epigastric pain. In October 1985 and October 1986, upper gastrointestinal endoscopy showed gastric erosions and biopsies showed gastritis. In January 1987 epigastric pain was investigated with upper gastrointestinal endoscopy and biopsies; gastritis with $H$ pylori was present, and he was treated with cimetidine. In May and November 1987, because of persistent epigastric pain, two additional upper gastrointestinal endoscopies showed gastritis with $H$ pylori. He was treated with successive courses of ranitidine, famotidine and sulcrate. In June 1988 and May 1989, epigastric pain was still present, and upper gastrointestinal endoscopy on both occasions showed gastritis with no $H$ pylori seen. Another upper gastrointestinal endoscopy with biopsies done in September 1990 because of epigastric pain showed gastritis with $\mathrm{H}$ pylori. He was treated with successive courses of sulcrate, cimetidine, domperidone maleate and omeprazole $20 \mathrm{mg} /$ day. Epigastric pain subsided. In early September 1993 epigastric pain recurred; upper gastrointestinal endoscopy and biopsies showed a gastric body polyp and gastritis with $\mathrm{H}$ pylori. Omeprazole $20 \mathrm{mg} /$ day was prescribed for 28 days. In late September 1993 upper gastrointestinal endoscopy demonstrated gastritis with no $\mathrm{H}$ pylori, a benign resected gastric body polyp and inflammatory changes present only with no H pylori. Omeprazole $20 \mathrm{mg} /$ day was continued. In March 1995 upper gastrointestinal endoscopy and biopsies of the gastric antrum showed gastritis but no H pylori.

Case 12: A 53-year-old male was evaluated for abdominal pain; he previously had a duodenal ulcer. In April 1984 upper gastrointestinal endoscopy and biopsies showed gastritis. In February 1987, because of epigastric pain, upper gastrointestinal endoscopy and biopsies were done and showed gastritis. In January 1992 epigastric pain recurred; upper gastrointestinal endoscopy showed gastritis with $H$ pylori. Treatment consisted of courses of sulcrate, ranitidine, famotidine and, finally, omeprazole $20 \mathrm{mg} /$ day for 28 days. His pain resolved. In June 1992 another upper gastrointestinal endoscopy showed gastritis in the gastric antrum but no $\mathrm{H}$ pylori. Gastric body biopsies were normal. In August 1993 epigastric pain developed. Upper gastrointestinal endoscopy and biopsies showed gastritis with $H$ pylori. No attempt was made to characterize the $H$ pylori strain specifically. He was treated with omeprazole $20 \mathrm{mg} /$ day for 28 days. His pain resolved again but then recurred in February 1994. Upper gastrointestinal endoscopy showed gastric and duodenal erosions with gastric ulcer and duodenal ulcer, but biopsies of the adjacent mucosa in the gastric antrum and gastric body were normal with no H pylori.

\section{DISCUSSION}

In this study, $12 \mathrm{H}$ pylori-positive patients were later observed to have $H$ pylori-negative gastric biopsies even though antibiotics were not administered for $\mathrm{H}$ pylori eradication. The findings in the present study were based on direct detection of $H$ pylori using both hematoxylin and eosin-stained and silver-stained serially sectioned biopsy sections; prior studies have indicated that silver-stained biopsies alone are most sensitive for $\mathrm{H}$ pylori detection in gastric mucosa (5). Although $H$ pylori appears to be more difficult to detect after omeprazole treatment in some patients, it appears that $H$ pylori may 'spontaneously' or normally disappear from the gastric mucosa of patients with gastritis or ulcer disease.

Although 188 patients had at least two endoscopic procedures with gastric biopsies, only 12 patients $(6.4 \%)$ fulfilled the specific inclusion criteria for this study; others were excluded by the finite time lines of the study or if they received antibiotics. Thus, the true frequency of this $\mathrm{H}$ pylori disappearance during the three- to four-year period of the present study is unknown. In a retrospective, long term study of 39 patients with H pylori-associated gastritis (12), however, complete 'healing' of $H$ pylori occurred in five patients $(13 \%)$ with no antibiotic therapy. Other studies have also suggested apparent spontaneous disappearance of $\mathrm{H}$ pylori, either serologically during a mean follow-up of 11.5 years (13) or histologically over six years (14) in about $5 \%$ to $10 \%$ of patients. Finally, retrospective epidemiological data suggest that spontaneous resolution of $H$ pylori may commonly occur in otherwise healthy people (15). A long term prospective study, possibly employing different direct and indirect $H$ pylori detection methods, will be needed to evaluate fully the true natural history of this intriguing gastric mucosal organism.

In the present study, 10 of the 12 patients were treated with omeprazole for at least one month after the first endoscopic procedure, while two received no medication (ie, one was treated with added dietary fibre for diverticular disease and one with a gluten-free diet for celiac disease). Although $H$ pylori may have been eradicated in some of these patients due to an omeprazole effect, the mechanism for this in vivo eradication of $H$ pylori is not clear (16). Both omeprazole and lansoprazole have demonstrated antibacterial activity in vitro $(17,18)$, possibly due to a direct toxic effect. This may be mediated by an inhibitory effect on $H$ pylori urease-dependent (19) or -independent mechanisms (20). Potent antisecretory activity and resultant effect on gastric $\mathrm{pH}$ may also be important, possibly by altering intracellular ammonia accumulation by $H$ pylori (21) or enhancing host defence mechanisms (16). Interestingly, omeprazole can reduce $H$ pylori density in vivo (22), and short term lansoprazole demon- 
strates activity against $H$ pylori in vivo (23). The present study, therefore, provides in vivo evidence that, in some (but not all) patients disappearance of $H$ pylori from serial gastric biopsies may have been due to a direct effect of omeprazole on $\mathrm{H}$ pylori.

Although a systematic topographical evaluation of all areas of the gastric mucosa was not done, multiple biopsies were obtained to obviate sampling error. On the second endoscopy all patients had at least two antral biopsies to eliminate potential sampling error in the gastric antrum (24) and the reported differences in regional expression of $\mathrm{H} p y$ lori-associated gastritis (7). In addition, seven of the 12 patients had biopsies obtained from both gastric antrum and gastric body. Sampling from the gastric mucosa in this fashion has been shown to reduce sampling error related to the potentially patchy distribution of $H$ pylori (25). In addition, there is some evidence that administration of omeprazole $40 \mathrm{mg} /$ day - but not omeprazole $20 \mathrm{mg} /$ day, as used in this study - may alter the intragastric distribution of $H$ pylori from gastric antral to gastric body mucosa (26).

In cases 1 and 12 it was particularly intriguing that recurrent $H$ pylori was evident with repeated endoscopic evaluations. This finding could represent reinfection with the same strain of $H$ pylori that was initially detected or a second $H$ pylori strain. Future studies may necessarily employ specific typing methods to define specific $H$ pylori strains. $H$ pylori can be typed by polymerase chain reaction-restriction fragment length polymorphism of urease or other genes, and by RNA gene probes and Southern blot hybridization (ribotyping) (27). In one recent study, for example,

\section{REFERENCES}

1. Warren JR. Unidentified curved bacilli on gastric epithelium in active chronic gastritis. Lancet 1983;i:1273.

2. Marshall B. Unidentified curved bacilli on gastric epithelium in active chronic gastritis. Lancet 1983;i:1273-5.

3. Marshall BJ, Armstrong JA, McGechie DB, Glancy RJ. Attempt to fulfil Koch's postulates for pyloric campylobacter. Med J Aust 1985;142:436-9.

4. Morris A, Nicholson G. Ingestion of Campylobacter pyloridis causes gastritis and raised fasting gastric $\mathrm{pH}$. Am J Gastroenterol 1987;82:192-9.

5. Cutler AF, Havstad S, Ma CK, Blaser MJ, Perez-Perez GI, Schubert TT. Accuracy of invasive and noninvasive tests to diagnose Helicobacter pylori infection. Gastroenterology 1995;109:136-41.

6. Morris A, Ali MR, Brown P, Lane M, Patton K. Campylobacter pylori infection in biopsy specimens of gastric antrum: Laboratory diagnosis and estimation of sampling error. J Clin Pathol 1989;42:727-32.

7. Bayerdorffer E, Lehn N, Hatz R, et al. Difference in expression of Helicobacter pylori gastritis in antrum and body. Gastroenterology 1992;102:1575-82

8. Gustavsson S, Phillips SF, Malagelada JR, Rosenblatt JE. Assessment of Campylobacter-like organisms in the postoperative stomach, iatrogenic gastritis, and chronic gastroduodenal diseases: Preliminary observations. Mayo Clin Proc 1987;62:265-8.

9. Wolber R, Owen D, Freeman HJ. Colonic lymphocytosis in patients with celiac sprue. Hum Pathol 1990;21:1092-6.

10. Wolber R, Owen D, DelBuono L, Appelman H, Freeman HJ. Lymphocytic gastritis in patients with celiac sprue or sprue-like intestinal disease. Gastroenterology 1990;98:310-5.

11. Dixon MF, Wyatt JI, Burke DA, Rathbone BJ. Lymphocytic gastritis relationship to Campylobacter pylori infection. J Pathol 1988;154:125-32.

12. Niemela S, Karttunen T, Kerola T. Helicobacter pylori-associated gastritis. Evolution of histologic changes over 10 years. Scand J Gastroenterol 1995;30:542-9. analysis of ribosome patterns revealed a complex pattern of $\mathrm{H}$ pylori in the stomachs of the same individuals and suggested multiple sources of infection due to different strains (28).

In a recent review (29) evidence related to the opportunistic, rather than the pathogenic, role of $\mathrm{H}$ pylori in a number of gastrointestinal disorders was critically examined. It was concluded that it is premature to suggest any specific eradication regimen since there is still no consensus on symptoms, etiology or natural history for patients with gastritis. In a Danish study of 30 healthy adults without gastrointestinal symptoms, it was observed that the average age of patients with gastritis alone was substantially less than that of patients with $H$ pylori (30). It was concluded that $H$ pylori was not the cause of the gastritis, but rather that the gastritis was a prerequisite for $\mathrm{H}$ pylori gastric mucosal colonization. In the present report, review of the endoscopic findings and gastric biopsy changes at the time that $H$ pylori was no longer detectable revealed 'concordant' observations in only five patients, ie, no macroscopic or microscopic gastric pathology at the time that $H$ pylori was absent. Seven patients had 'discordant' findings, ie, evidence of definite gastric pathology, either gastric ulceration or gastritis, even though $\mathrm{H}$ pylori was no longer detectable in the gastric mucosa. Considered with the apparent discrepant observations from older clinical trials (31) and the lack of evidence, even from a recent well-designed clinical trial in $H$ pylori-associated gastritis (32), additional prospective studies are needed to improve our understanding of the precise pathogenic role for $\mathrm{H}$ pylori in gastritis.

13. Kuipers EJ, Pena AS, van Kamp G, et al. Seroconversion for Helicobacter pylori. Lancet 1993;342:328-31.

14. Villako K, Maaroos H, Tammur R, et al. Helicobacter (Campylobacter) pylori infestation and the development and progression of chronic gastritis: Results of long-term follow-up examinations of a random sample. Endoscopy 1990;22:114-7.

15. Meyer B, Werth B, Beglinger C, et al. Helicobacter pylori in healthy people: a dynamic process? Gut 1991;32:347-50.

16. Hunt RH. pH and Hp-gastric acid secretion and Helicobacter pylori: implications for ulcer healing and eradication of the organism. Am J Gastroenterol 1993;88:481-3.

17. Iwahi T, Satoh H, Nakao M, Iwasaki T, et al. Lansoprazole, a novel benzimidazole proton pump inhibitor, and its related compounds have selective activity against Helicobacter pylori. Antimicrob Agents Chemother 1991;35:490-6.

18. Megraud F, Boyanova L, Lamouliatte H. Activity of lansoprazole against Helicobacter pylori. Lancet 1991;337:1486.

19. Nagata K, Satoh H, Iwahi T, Shimoyama T, Tamura T. Potent inhibitory action of the gastric proton pump inhibitor lansoprazole against urease activity of Helicobacter pylori: unique action selective for $\mathrm{H}$ pylori cells. Antimicrob Agents Chemother 1993;37:769-74.

20. McGowan CC, Cover TL, Blaser MJ. The proton pump inhibitor omeprazole inhibits acid survival of Helicobacter pylori by a urease-independent mechanism. Gastroenterology 1994;107:738-43.

21. Neithercut WD, Greig MA, Hossack M, McColl KE. Suicidal destruction of Helicobacter pylori: metabolic consequences of intra cellular accumulation of ammonia. J Clin Pathol 1991;44:380-4.

22. Stolte M, Bethke B. Elimination of Helicobacter pylori under treatment with omeprazole. Z Gastroenterol 1990;28:271-4.

23. Jhala NC, McFarland MM, Brightman SA, Morale B, Rubin W, Atkinson BF. The effects of short-term lansoprazole therapy on Helicobacter pylori infection and antral gastritis in duodenal ulcer patients. Am J Gastroenterol 1995;90:1824-8.

24. Morris A, Ali MR, Brown P, Lane M, Patton K. Campylobacter pylori 
infection in biopsy specimens of gastric antrum: laboratory diagnosis and estimation of sampling error. J Clin Pathol 1989;42:727-32.

25. Bayerdorffer E, Oertel H, Lehn N, et al. Topographic association between active gastritis and Campylobacter pylori colonisation. J Clin Pathol 1989;42:834-9.

26. Logan RPH, Walker MM, Misiewicz JJ, Gummett PA, Karim QN, Baron JH. Changes in the intragastric distribution of Helicobacter pylori during treatment with omeprazole. Gut 1995;36:12-6.

27. Clayton CL, Kleanthouse H, Morgand D, Puckey L, Tabaqchali S. Rapid fingerprinting of Helicobacter by polymerase chain reaction and restriction fragment length polymorphism analysis. J Clin Microbiol 1993;31:1420-5.

28. Owen RJ, Desai M, Figura N, et al. Comparison between degree of histological gastritis and DNA fingerprints, cytotoxicity and adhesivity of Helicobacter pylori from different gastric sites. Eur J Epidemiol 1993;9:315-21.

29. Graham JR. Helicobacter pylori: human pathogen or simply an opportunist? Lancet 1995;345:1095-7.

30. Fallingborg J, Poulsen LO, Grove A, Stubbe Teglbjaerg PS. Frequency of Helicobacter pylori and gastritis in healthy subjects without gastrointestinal symptoms. Scand J Gastroenterol 1992;27:388-90.

31. Talley NJ. A critique of therapeutic trials in Helicobacter pylori-positive functional dyspepsia. Gastroenterology 1994;106:1174-83.

32. Van Zanten SV, Malatjalian D, Tanton R, Leddin D, Hunt RH, Blanchard W. The effect of eradication of Helicobacter pylori on symptoms of non-ulcer dyspepsia: a randomized double-blind placebo controlled trial. Gastroenterology 1995;108:A250. 


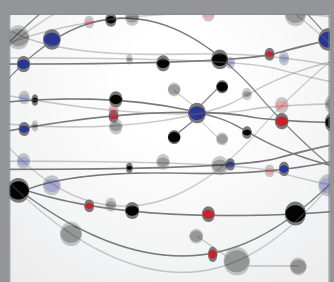

The Scientific World Journal
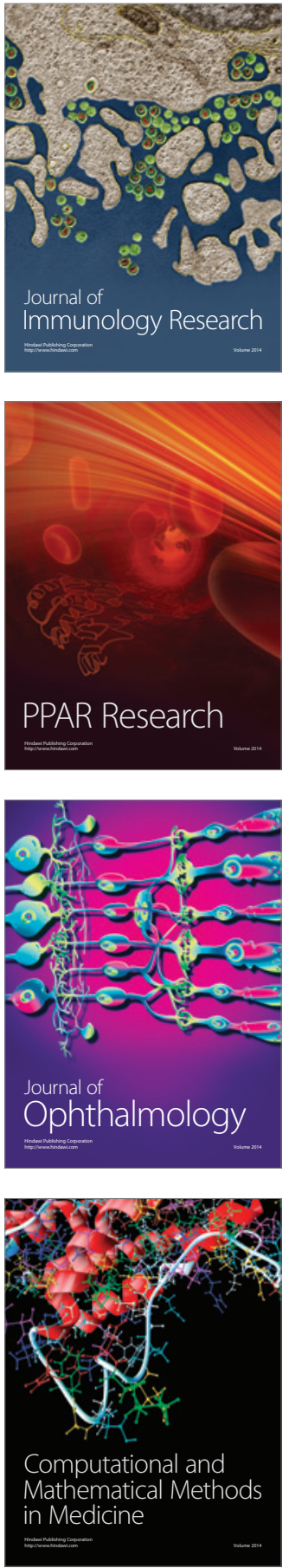

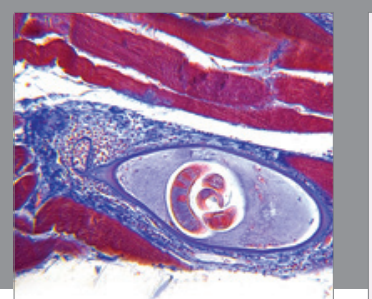

Gastroenterology Research and Practice

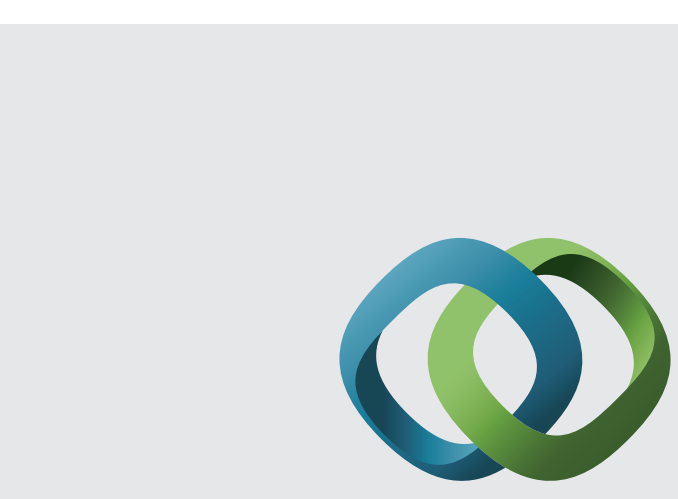

\section{Hindawi}

Submit your manuscripts at

http://www.hindawi.com
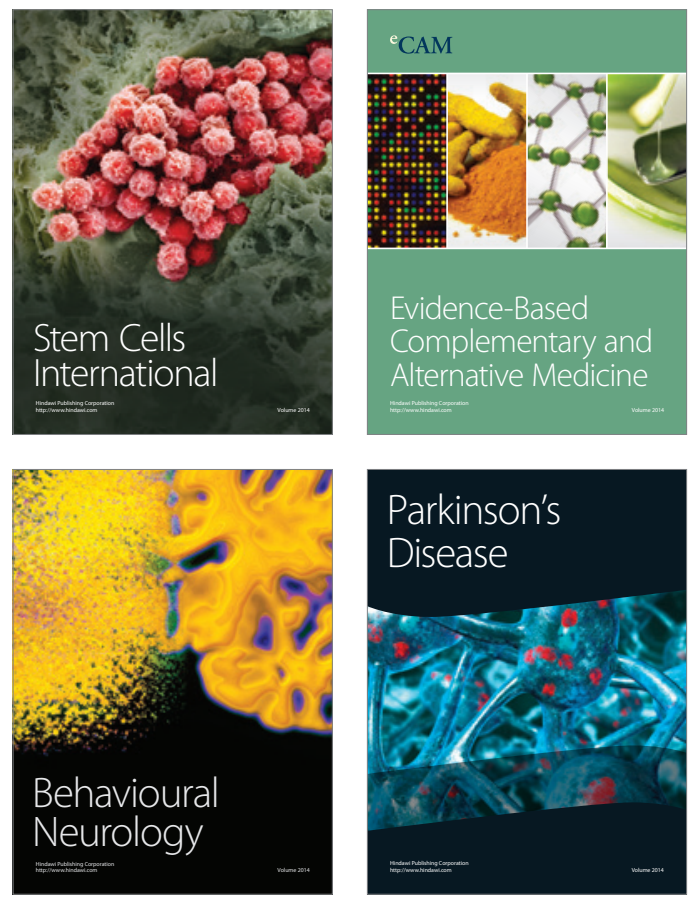
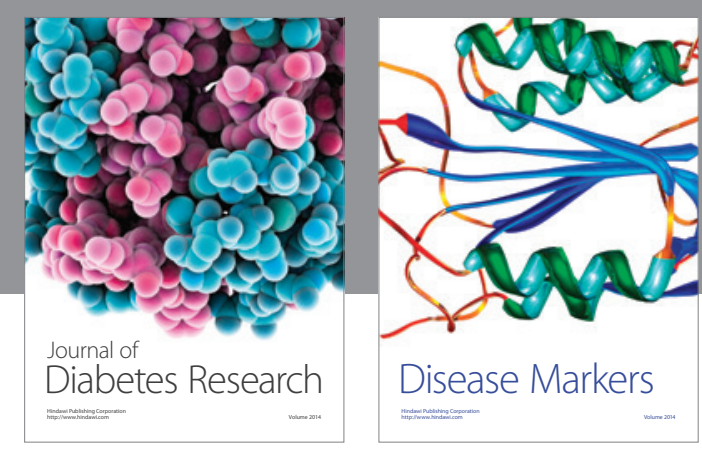

Disease Markers
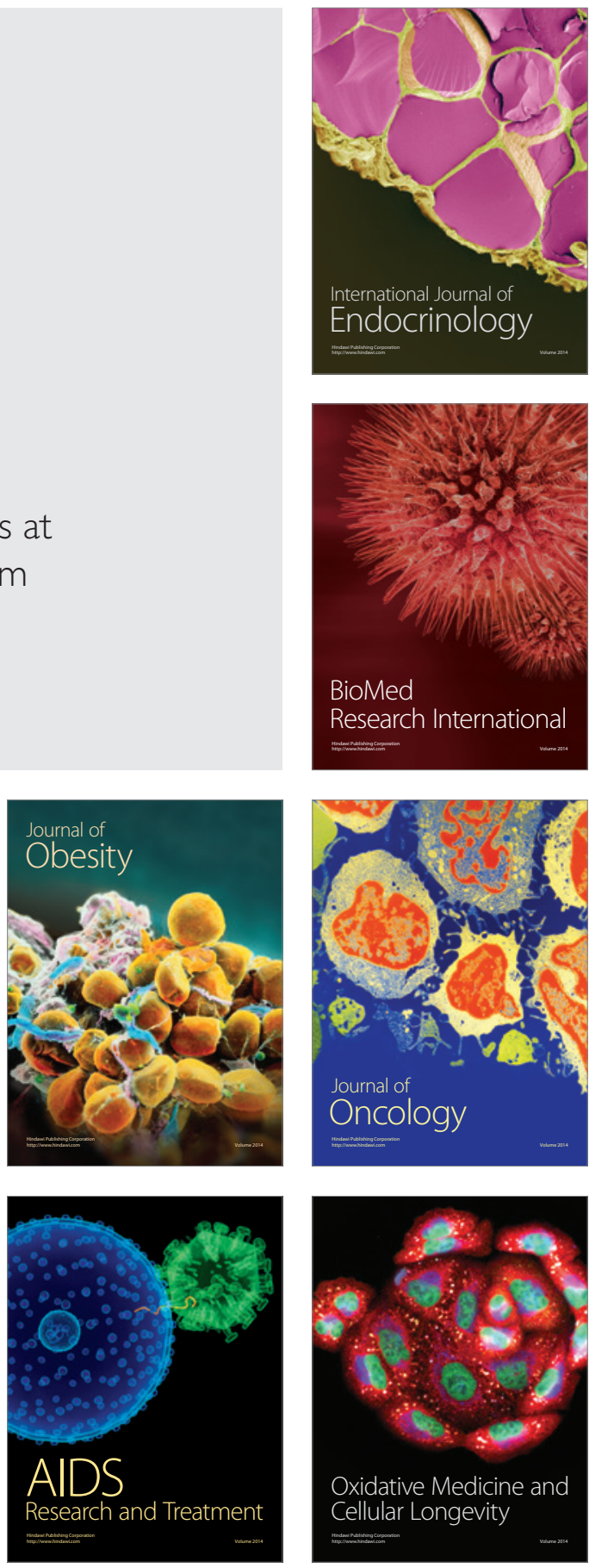